\title{
Hubungan Derajat Nyeri Dismenorea terhadap Penggunaan Obat Anti Inflamasi Non Steroid
}

\author{
Mutya Restu Ayu ${ }^{1}$, Yustini Alioes ${ }^{2}$, Rahmatini $^{3}$
}

\begin{abstract}
Abstrak
Dismenorea merupakan penyebab tersering masalah ginekologi pada wanita muda. Nyeri dismenorea membutuhkan penjabaran derajat nyeri yang cermat guna pemilihan terapi yang sesuai. Terapi yang paling banyak dipilih untuk mengatasi dismenorea adalah Obat Anti Inflamasi Non Steroid (OAINS). Tujuan penelitian ini adalah untuk menilai hubungan antara derajat nyeri dismenorea dan penggunaan OAINS. Desain penelitian menggunakan cross-sectional study dengan populasi adalah mahasiswi preklinik pendidikan dokter Universitas Andalas angkatan 2010-2012 sejumlah 555 orang. Teknik pengambilan sampel menggunakan teknik total sampling sehingga subjek merupakan seluruh populasi yang sudah memenuhi kriteria inklusi. Instrument dalam penelitian ini ialah kuisioner. Data dianalisis dengan uji korelasi spearman rank dengan $r<0,05$ untuk signifikansi. Hasil analisis univariat menunjukkan derajat intensistas nyeri yaitu 84 responden $(27,3 \%)$ nyeri ringan, 189 responden $(61,4 \%)$ nyeri sedang dan 35 responden $(11,4 \%)$ nyeri berat. 70 responden $(22,7 \%)$ memilih terapi OAINS. Hasil analisis bivariat menunjukkan nilai korelasi spearman rank 0,280 yang berarti adanya korelasi yang cukup antara derajat nyeri dismenorea dengan penggunaan OAINS.
\end{abstract}

Kata kunci: dismenorea, derajat nyeri dismenorea, OAINS.

\section{Abstract}

Dysmenorrhea is the common cause of gynecological problems in young women. The pain caused by dysmenorrhea requires a careful elaboration of the pain intensity level in order to choose the appropriate therapy. The most chosen therapy is Non-steroidal anti-inflammatory drugs (NSAIDs). The objective of this study was to assess the correlation between the pain intensity level of dysmenorrhea with the use of NSAIDs. This was a cross-sectional study with the population of 555 preclinical medical students in Medical Faculty of Andalas University class 2010-2012. The sampling technique was total population sampling with fulfilled inclusion criteria. The instrument in this study was a questionnaire. Data were analyzed with Spearman rank correlation test with $r<0.05$ for significance. The result of univariate analysis showed that the pain intensity level of dysmenorrhea was mild in 84 respondents (27.3\%), moderate in 189 respondents (61.4\%) and severe in 35 respondents (11.4\%). 70 respondents (22.7\%) chose NSAIDs as the therapy. The result of bivariate analysis showed that the value of spearman correlation was 0.280 meaning that there was a quite correlation between pain intensity level of dysmenorrhea and the use of NSAIDs.

Keywords: dysmenorrhea, the pain intensity level of dysmenorrhea, NSAIDs

Affiliasi penulis: 1. Pendidikan Dokter FK UNAND (Fakultas Kedokteran Universitas Andalas Padang), 2. Bagian Biokimia FK UNAND, 3. Bagian Farmakologi FK UNAND

Korespondensi: Mutya Restu Ayu, E-mail : Mutyarestuayu@gmail.com, Telp : 085264775502

\section{PENDAHULUAN}

Menstruasi adalah perdarahan yang terjadi secara periodik dan siklus dari uterus serta bersamaan dengan pelepasan endometrium. Pada kebanyakan wanita tidak merasakan keluhan pada waktu 
menstruasi akan tetapi sebagian kecilnya mengeluh rasa tidak enak di perut bawah sebelum dan selama haid yang diikuti rasa mual, hal ini dikenal dengan istilah dismenorea. Dismenorea terbagi menjadi menjadi dua yaitu dismenorea primer dan sekunder. Dismenorea primer merupakan kondisi dismenorea yang esensial dan idiopatik serta tidak berhubungan dengan kelainan ginekologik, sedangkan dismenorea sekunder disebabkan oleh kelainan ginekologik seperti endometriosis, salpingitis kronika dan lain sebagainya. Dismenorea merupakan penyebab tersering masalah ginekologi pada wanita muda untuk bertemu dokter karena gangguan yang ditimbulkan bersifat subyektif, berat dan intensitasnya sulit untuk dinilai. ${ }^{1}$

Prevalensi dismenorea primer cenderung lebih tinggi pada wanita muda dibanding dengan wanita dewasa dengan perkiraan persentase 20\% hingga 90\%. Di Swedia prevalensi dismenorea pada usia 19 tahun sebanyak $90 \%$ dan usia 24 tahun sebanyak $67 \% .^{2}$ Di Kanada sekitar $60 \%$ responden mengalami dismenorea primer dengan 51\% diantaranya melaporkan mengalami keterbatasan kegiatan seharihari dan $17 \%$ melaporkan absen dari sekolah atau kantor. $^{3}$ Di Indonesia menurut penelitian yang dilakukan di Desa Banjar Kemantren didapatkan kejadian dismenorea primer banyak terjadi pada wanita dengan golongan umur 21-25 tahun, sebanyak $71,0 \%$ responden mengalami dismenorea primer dengan $96,8 \%$ diantaranya mengalami keluhan dismenorea primer pada <24 jam dari mulai menstruasi. 4

Rasa nyeri pada menstruasi dapat ditangani dengan beberapa terapi diantaranya terapi analgesik, terapi hormonal, kompres panas pada perut bawah, terapi obat nonsteroid antiprostaglandin dan dilatasi kanalis servikalis. ${ }^{1}$ Terapi yang paling efektif untuk dismenorea primer adalah terapi OAINS dengan mekanisme penghambatan produksi prostaglandin yang menyebabkan nyeri. ${ }^{5}$ Mekanisme kerja OAINS adalah dengan menghambat enzim siklooksigenase sehingga terganggunya konversi asam arakidonat menjadi Prostaglandin G2, Prostaglandin H2 dan Tromboksan A2 yang berkontribusi dalam menimbulkan nyeri. Kemanjuran terapi OAINS pada terapi dismenorea primer diatas $85 \%$ dalam mengurangi nyeri. ${ }^{6}$

\section{Stres dapat mempengaruhi kejadian} dismenorea yaitu dalam keadaan stress akan terjadi pengeluaran prostaglandin yang dapat memicu kontraksi miometrium dan vasokonstriksi pembuluh darah sehingga dapat menimbulkan nyeri. ${ }^{7}$ Survei awal yang dilakukan terhadap mahasiwi Fakultas Kedokteran Universitas Andalas mendapatkan bahwa 13 dari 15 orang mengalami dismenorea dan 8 diantaranya mengkonsumsi OAINS guna menanggulangi nyeri yang dirasakan. Mahasiswa fakultas kedokteran memiliki kecendrungan lebih tinggi untuk mengalami stres, penyebab stres yang terjadi dapat berasal dari dalam diri maupun dari luar, misalnya karena besarnya tuntutan orang tua atas prestasi akademik sehingga menyebabkan stress. ${ }^{8}$ Penelitian mengenai prevalensi stres yang terjadi pada mahasiswi kedokteran telah dilakukan oleh beberapa peneliti. Di Saudi Arabia prevalensi mahasiswa fakultas kedokteran mengalami stres ringan 20,4\%, stres sedang $18,2 \%$ dan stres tinggi $25,2 \%{ }^{9}$

Berdasarkan uraian diatas maka perlu untuk meneliti hubungan derajat nyeri dismenorea terhadap penggunaan OAINS mahasiswi preklinik pendidikan dokter Fakultas Kedokteran Universitas Andalas angkatan 2010-2012. Pemilihan mahasiswi preklinik sebagai subjek penelitian karena menghindari kesulitan saat penelitian yang menggunakan metode wawancara dan pengisian kuisioner.

\section{METODE}

Jenis penelitian adalah studi analitik dengan pendekatan cross sectional study. Penelitian ini dilakukan pada seluruh mahasiswi pre-klinik Program Pendidikan Dokter Fakultas Kedokteran Universitas Andalas Angkatan 2010-2012 sejumlah 555 orang. Teknik pemilihan subjek menggunakan teknik total sampling sehingga subjek merupakan seluruh populasi yang sudah memenuhi kriteria inklusi. Instrument penelitian berupa kuisioner yang dilaksanakan dari Januari 2013 - Mei 2013 di Fakultas Kedokteran Universitas Andalas.

Penelitian ini menggunakan analisis univariat yang dilakukan untuk melihat frekuensi data kategorik, dan nilai mean, median, standar deviasi, nilai maksimum, dan nilai minimum untuk data numerik. Analisis bivariat untuk melihat hubungan yang 
signifikan antara dua variabel yaitu derajat nyeri dismenorea dengan penggunaan OAINS. Analisis bivariat diuji statistik dengan korelasi spearman rank.

\section{HASIL}

Tabel 1. Distribusi responden berdasarkan Umur

\begin{tabular}{cll}
\hline Umur & Jumlah & $\%$ \\
\hline 17 tahun & 11 & 3,6 \\
18 tahun & 68 & 22,1 \\
19 tahun & 104 & 34,7 \\
20 tahun & 93 & 31,2 \\
21 tahun & 23 & 7,5 \\
22 tahun & 2 & 0,6 \\
23 tahun & 1 & 0,3 \\
\hline Total & 302 & 100
\end{tabular}

Berdasarkan Tabel 1 dapat dilihat jumlah responden terbanyak pada usia 19 tahun yaitu sebanyak 104 responden (33,8\%).

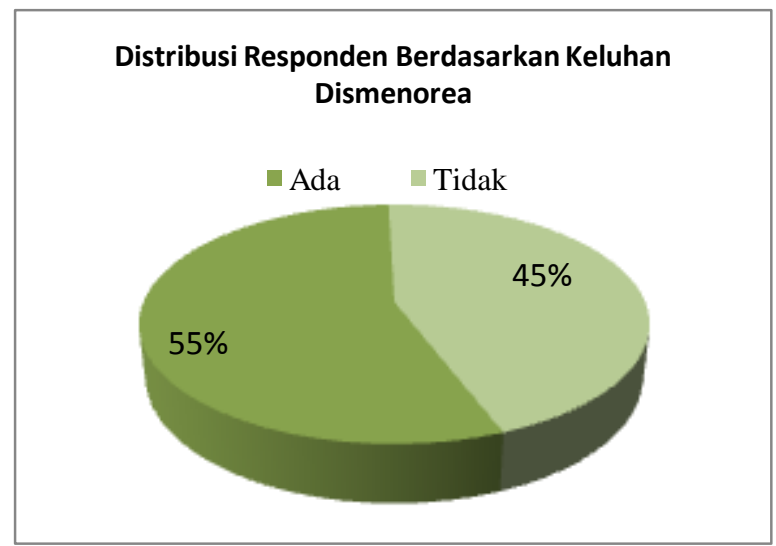

Gambar 1. Distribusi responden berdasarkan keluhan dismenorea

Berdasarkan Gambar 1 dapat dilihat bahwa responden terbanyak mengalami dismenorea yaitu 308 responden $(55,4 \%)$ dari total 555 responden.

Tabel 2. Distribusi frekuensi pemilihan OAINS

\begin{tabular}{lll}
\hline \multicolumn{1}{c}{ Jenis OAINS } & Jumlah & $\%$ \\
\hline Asetosal & 1 & 0,3 \\
Ibuprofen & 1 & 0,3 \\
Diklofenak & - & 0 \\
Asam Mefenamat & 57 & 18,5 \\
Parasetamol & 11 & 3,6 \\
Tidak menggunakan & 238 & 77,3 \\
\hline Total & 308 & 100 \\
\hline
\end{tabular}

Berdasarkan Tabel 2 dapat dilihat Asam mefenamat merupakan jenis OAINS yang terbanyak dipilih untuk terapi dismenorea.

\section{Analisis Univariat}

Analisis univariat berguna untuk melihat distribusi frekuensi masing-masing variabel yang diteliti yaitu derajat nyeri dismenorea dan penggunaan OAINS

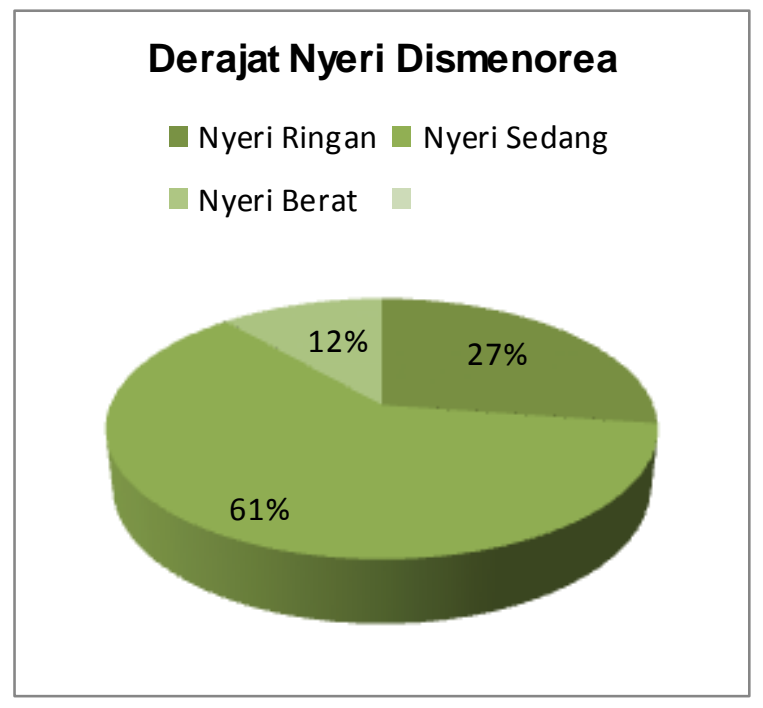

Gambar 2. Persentase derajat nyeri dismenorea

Berdasarkan Gambar 2 dapat dilihat bahwa responden terbanyak mengalami nyeri sedang yaitu $61,4 \%$.

Tabel 3. Distribusi frekuensi terapi dismenorea

\begin{tabular}{lll}
\hline \multicolumn{1}{c}{ Terapi } & Jumlah & $\%$ \\
\hline Non farmakologis & 238 & 77,3 \\
Farmakologis (OAINS) & 70 & 22,7 \\
\hline Total & 308 & 100 \\
\hline
\end{tabular}

Berdasarkan Tabel 3 terlihat bahwa sebagian besar responden memilih non farmakologis untuk terapi dismenorea yaitu 238 responden dari total 308 responden atau $77.3 \%$.

\section{Analisis Bivariat}

Analisis bivariat digunakan untuk melihat hubungan variabel independen (derajat nyeri dismenorea) dan variabel dependen (penggunaan OAINS). 
Tabel 4. Hubungan derajat nyeri dismenorea dengan penggunaan OAINS

\begin{tabular}{llrr}
\hline & Spearman's rho & $\begin{array}{c}\text { Intensitas } \\
\text { nyeri }\end{array}$ & $\begin{array}{c}\text { Terapi } \\
\text { dismenorea }\end{array}$ \\
\hline intensitas & Correlation & 1.000 & .280 \\
nyeri & Coefficient & & \\
& Sig. (2-tailed) &. & 0.000 \\
& $\mathrm{~N}$ & 308 & 308 \\
terapi & Correlation & 0.280 & 1.000 \\
dismenorea & Coefficient & & \\
& Sig. (2-tailed) & 0.000 &. \\
& $\mathrm{~N}$ & 308 & 308 \\
\hline
\end{tabular}

Berdasarkan uji normalitas didapatkan data terdistribusi tidak normal sehingga uji statistik dilakukan menggunakan uji korelasi spearman rank. Signifikansi lewat baris Sig. (2-tailed). Jika nilai Sig. (2tailed) $<0,05$, maka hubungan yang terdapat pada $r$ dianggap signifikan. Dari tabel 4. dapat dilihat nilai $r$ adalah 0,000. Artinya $0,000<0,05$ dan dengan demikian korelasi antara dua variabel signifikan.

Uji statistik spearman rank dapat ditentukan pula interval kekuatan hubungan/korelasi yaitu, bila nilai korelasi spearman 0 berarti tidak ada hubungan, nilai korelasi spearman 0,00 - 0,25 berarti korelasi sangat lemah, nilai korelasi spearman 0,25-0,50 berarti korelasi cukup, nilai korelasi spearman 0,500,75 berarti korelasi kuat, nilai korelasi spearman 0,75 0,99 berarti korelasi sangat kuat dan nilai korelasi spearman 1 berarti korelasi sempurna. Uji statistik yang telah dilakukan terdapat nilai korelasi spearman 0,280 berarti kekuatan korelasi cukup antara derajat nyeri dismenorea dengan penggunaan OAINS pada mahasiswi preklinik pendidikan dokter FK UNAND angkatan 2010-2012.

\section{PEMBAHASAN}

Berdasarkan penelitian yang telah dilakukan terhadap 555 responden, didapatkan 84 responden $(27,3 \%)$ mengalami nyeri ringan, 189 responden $(61,4 \%)$ mengalami nyeri sedang dan 35 responden $(11,4 \%)$ mengalami nyeri berat sehingga dapat disimpulkan bahwa responden terbanyak mengalami nyeri sedang. Hasil ini hampir sama dengan penelitian yang dilakukan oleh Unsal et al tahun 2010 pada mahasiswi Universitas Dumlupinar Turki yang mendapatkan sebanyak $66,2 \%$ responden dari total 623 responden. Penelitian tersebut juga menggunakan skala intensitas nyeri numerik sehingga penjabaran nyeri lebih cermat dan sesuai dengan pengalaman nyeri setiap individu yang berbeda. ${ }^{10}$

Analisis univariat yang juga dilakukan adalah gambaran penggunaan OAINS untuk terapi dismenorea. Didapatkan responden sebanyak 22,7\% memilih penggunakan terapi farmakologis yaitu OAINS untuk penanganan dismenorea dan 64\% diantaranya mengalami nyeri sedang. Hasil ini berbeda dengan penelitian yang dilakukan oleh Banikarim et al tahun 2000 pada remaja perempuan Spanyol yang mendapatkan $52 \%$ menggunakan terapi farmakologis guna pengobatan dismenorea. ${ }^{11}$ Berbeda pula dengan penelitian yang dilakukan oleh Zhou et al tahun 2010 pada mahasiswi Universitas China yang mendapatkan $8 \%$ responden memilih terapi farmakologis. ${ }^{12} \mathrm{Di}$ Indonesia, sebuah penelitian yang dilakukan oleh Lestari et al tahun 2010 remaja perempuan di manado mendapatkan sebanyak $13,1 \%$ responden menggunakan OAINS seperti parasetamol dan lainnya. ${ }^{13}$ Di FK UNAND, penelitian oleh Bahri tahun 2013 pada 96 responden mendapatkan sebanyak 38 responden atau 39,5\% mengonsumsi OAINS sebagai pilihan terapi dismenorea. ${ }^{14} \mathrm{Hal}$ ini dapat terjadi akibat adanya perbedaan ketahanan terhadap nyeri sehingga berbeda pula penanganan yang dipilih, selain itu pengetahuan indikasi obat dan efek samping yang turut mempengaruhi pilihan terapi dismenorea.

Hasil analisis bivariat dengan menggunakan uji statistik korelasi spearman rank diperoleh $r=0,000(r$ $<0,05)$ berarti terdapat korelasi antar dua variabel yang signifikan. Kekuatan korelasi dapat dilihat dari nilai korelasi spearman yang didapatkan yaitu 0,280 berarti hubungan derajat intensitas nyeri terhadap penggunaan OAINS pada mahasiswi preklinik pendidikan dokter FK UNAND angkatan 2010-2012 dinyatakan memiliki kekuatan korelasi yang cukup. Hasil ini diperkuat dengan penelitian Zhou et al pada tahun 2010 pada mahasiswi Universitas China yang mendapatkan adanya hubungan intensitas nyeri terhadap penggunaan OAINS yaitu semakin nyeri semakin banyak responden memilih menggunakan OAINS. $^{12}$ 


\section{KESIMPULAN}

Prevalensi dismenorea pada mahasiswi preklinik pendidikan dokter FK UNAND angkatan 2010-2012 sebanyak 55,4\% dengan intensitas nyeri sedang lebih banyak dibandingkan yang mengalami nyeri ringan dan nyeri berat. Sebanyak 22,7\% menggunakan OAINS sebagai terapi disemnorea. Jenis OAINS yang paling banyak digunakan yaitu Asam Mefenamat.

Terdapat hubungan yang cukup antara derajat nyeri dismenorea terhadap penggunaan OAINS pada mahasiswi preklinik pendidikan dokter FK UNAND angkatan 2010-2012

\section{UCAPAN TERIMA KASIH}

Ucapan terima kasih kepada Dra. Yustini Alioes, MSi. Apt dan dr. Rahmatini, M.Kes atas bimbingan, nasehat dan bantuannya dalam penelitian.

\section{DAFTAR PUSTAKA}

1. Wiknjosastro $H$, Saifuddin $A B$, Rachimhadhi $T$. IImu kandungan. Jakarta: PT. Bina Pustaka Sarwono Prawirodihardjo; 2009..

2. French L. Dysmenorrhea. American Family Physician. 2005; 71(2): 285-91.

3. Burnett MA, Antao V, Black A, Feldman K, Grenville $A$, Lea $R$, et al. Prevalence of primary dysmenorrhea in Canada. Journal of Obstetric and Gynaecology Canada. 2005;27:768.

4. Novia I, Puspitasari N. Faktor resiko yang mempengaruhi kejadian dismenorea primer. The Indonesian Journal Public Health. 2008;4(2):96104.

5. Marjoribanks J, Proctor ML, Farquhar C. Nonsteroidal anti-inflammatory drugs for primary dysmenorrhea. Cochrane Database System Revision (4).CD001751; 2003.
6. Livshits A, Sedman DS. Role of non-steroidal antiinflammatory drugs in gynaecology. Pharmaceuticals. 2010:2082-9.

7. Speroff L, Marck AF. Clinical gynaecologic endocrinology and infertility. Philadelphia; 2005.

8. Carolin. Gambaran tingkat stres pada mahasiswa pendidikan sarjana kedokteran Universitas Sumatera Utara (skripsi). Medan: Universitas Sumatera Utara; 2010.

9. Abdulghani HM, Alkanhal AA, Mahmoud ES, Ponnamperuma GG, Alfaris EA. Stress and its effects on medical students: a cross-sectional study at a college of medicine in Saudi Arabia. Journal of Health, Population and Nutrition. 2011; 29(5):516-22.

10. Unsal A, Atranci U, Tozun M, Arslan G, Calik E. Prevalences of dysmenorrhea and it's effect on quality of life among a group of female university students. Upsala Journal of Medical Sciences. 2010:115(2):138-45

11. Banikarim C, Chacko MR, Kelder SH. Prevalence and impact of dysmenorrhea on Hispanic female adolescents. Arch Pediatric Adolescent Medicine. 2000;154(12):1226-9.

12. Zhou H, Yang ZW, Group S. Prevalence of dysmenorrhea in female students in a Chinese University. Health. 2010;2(4):311-4.

13. Lestari H, Metusala J, Suryanto DY. Gambaran dismenorea pada remaja putri sekolah menengah pertama di Manado. Jurnal Sari Pediatri. 2010; 12 (2):99-102

14. Bahri AA. Hubungan antara kebiasaan olahraga dengan dismenorea pada mahasiswi fakultas kedokteran program studi pendidikan dokter Universitas Andalas tahun ajaran 2012-2013 (skripsi). Padang: Universitas Andalas; 2013. 